\title{
GMR
}

\section{Relationship between perioperative cardiovascular risk factors and bone marrow cells from patients undergoing coronary artery bypass grafting surgery}

\author{
L. Zhang*, R. Wang*, C.-S. Xiao, Y. Wu and C.-Q. Gao \\ Department of Cardiovascular Surgery, PLA General Hospital Beijing, Beijing, China \\ *These authors contributed equally to this study. \\ Corresponding author: C.-Q. Gao \\ E-mail: gaochqing_ı@163.com \\ Genet. Mol. Res. 14 (4): 15233-15241 (2015) \\ Received May 28, 2015 \\ Accepted September 30, 2015 \\ Published November 25, 2015 \\ DOI http://dx.doi.org/10.4238/2015.November.25.11
}

ABSTRACT. Cell therapy through the implantation of autologous bone marrow cells has long been used in clinical trials for the treatment of ischemic heart diseases. However, as the outcomes of cell implantation vary among patients, risk factors that might influence the level and function of bone marrow progenitor cells should be determined, to identify patients who would benefit the most from this treatment. We collected clinical and laboratory data from 44 patients scheduled to undergo sternotomy for coronary artery bypass grafting (CABG). Bone marrow was aspirated from the sternum during the operation, and bone marrow mononuclear cells (BMMNCs) were isolated through density centrifugation. A negative correlation was observed between the number of BMMNCs and age $(\mathrm{N}=44, \mathrm{r}=-0.788, \mathrm{P}=0.001)$. The level of CD34+ cells in BMMNCs was $0.94 \pm 0.39 \%$, CD133+ cells $0.46 \pm 0.28 \%$, and CD34+CD133+ cells $0.53 \pm 0.26 \%$. The levels of CD34+ and CD133+ cells in diabetic patients were significantly lower than those in nondiabetic patients. Female gender, advanced age, and poor heart function were related with reduced 
progenitor cell clonogenic function. A positive correlation was observed between the level of CD34+ cells and BMMNC migration ability. Aging and diabetes were the major risk factors that influence the level and function of bone marrow resident progenitor cells in patients with coronary heart disease undergoing CABG. Further study is needed to determine whether these two factors can influence the outcome of bone marrow cell therapy for ischemic heart disease.

Key words: Ischemic heart disease; Bone marrow mononuclear cells; Cell therapy

\section{INTRODUCTION}

Cell therapy through the implantation of autologous bone marrow progenitor cells has been used for the treatment of ischemic heart diseases in clinical trials for decades. The initial preclinical studies have used human cells isolated from healthy young humans or young mice. When investigators started to isolate patient-derived cells, it became obvious that the number and functional activity of the cells are significantly impaired in comparison to healthy controls (Vasa et al., 2001b; Tepper et al., 2002). However, as the outcomes of cell implantation obviously vary among patients with cardiovascular risk factors, it is essential to identify the risk factors that might influence the level and function of progenitor cells in the bone marrow, so as to identify those patients who would benefit the most from this treatment.

\section{MATERIAL AND METHODS}

\section{Patient population}

Forty-four patients undergoing elective coronary artery bypass grafting (CABG) were studied. The patients were operated on between October 2010 and May 2011. Thirty-two patients underwent CABG with cardiopulmonary bypass, and 12 underwent off-pump CABG. The exclusion criteria were acute coronary syndrome, chronic renal failure, cancer, treatment with immunomodulating agents, and active infection. All patients received general anesthesia with a routine protocol; patients undergoing on-pump CABG were managed according to a standard protocol, namely mild systemic hypothermia $\left(35^{\circ} \mathrm{C}\right)$ with perfusion pressure maintained at about $60 \mathrm{mmHg}$. Cardiac arrest was achieved with an antegrade cold cardioplegic solution. Off-pump surgery was performed by using a stabilizer. Antiplatelet agents were discontinued at least 5 days before surgery. Statin therapy was continued until the day before surgery and reinstituted before discharge.

After surgery, none of the patients in our cohort required reexploration for bleeding or renal replacement therapy. None of the patients had cardiovascular complications or developed any form of septicemia. Ethical approval was granted by the local research ethics committee. All participants gave their written informed consent.

\section{Clinical and laboratory data of patients}

We collected all clinical and laboratory data that could probably affect bone marrow progenitor cells; this included demographics and clinical characteristics, as well as routine 
laboratory examinations. The demographics and clinical factors were recorded by doctors. The routine laboratory examinations were performed at our hospital.

\section{Sample collection}

Blood samples $(10 \mathrm{~mL})$ were collected from a peripheral vein before surgery. Bone marrow aspirates $(40 \mathrm{~mL})$ were collected from manubrium sternum through two to three punches with a $14 \mathrm{G}$ marrow needle. The technique of marrow aspiration used in this study is an established technical approach for collecting marrow samples and has been used in research studies previously.

\section{Cell isolation}

Bone marrow mononuclear cells (BMMNCs) were isolated as described previously (Van Ramshorst et al., 2009). Briefly, bone marrow aspirates were diluted with $0.9 \%$ sodium chloride (1:1), and mononuclear cells were isolated by means of density gradient centrifugation ( $400 \mathrm{~g}$, 30 min, without brake) by using Lymphoprep (GE Healthcare Bio-Sciences AB, Sweden). The mononuclear cells were washed three times with heparinized saline $(400 \mathrm{~g})$, counted, filtrated (100 $\mu \mathrm{m})$, and used for the experiments. To assess reproducibility, we determined the BMMNC counts twice in two separate $20 \mathrm{~mL}$ bone marrow samples.

\section{Flow cytometry analysis of BMMNCs}

Isolated mononuclear cells were labeled for 10 min with directly conjugated antibodies against human CD34 (fluorescein isothiocyanate [FITC] labeled; $10 \mu \mathrm{L}$, Becton Dickinson, Shanghai, China), CD133 [phycoerythrin (PE) labeled; $10 \mu \mathrm{L}$, Becton Dickinson], and CD45 (PE-labeled, $10 \mu \mathrm{L}$, Becton Dickinson) in manufacturer-recommended concentrations. Isotype-matched FITC- and PEconjugated antibodies (Miltenyi Biotec, Shanghai, China) were used as controls in all flow cytometry experiments. The samples were analyzed by using a BD FACSCalibur flow cytometer (BD Biosciences, Mississauga, Ontario, Canada). Cell fluorescence was measured immediately after staining, and data were analyzed with CellQuest software (FACSCalibur, Becton Dickinson). Progenitor cells were identified within lymphocyte clusters selected by using forward and side scatter as CD34, CD133, and CD34CD133, and presented as percentages of $1 \times 10^{5}$ cells acquired per sample.

\section{Migration}

BMMNC migration in response to SDF-1 was assessed by using 24-well Corning-Costar Transwell (Corning Costar, Acton, MA, USA) migration chambers (8-m pore size). The cells $\left(1 \times 10^{5}\right)$ were placed in the insert in $100 \mu \mathrm{L}$ serum-free medium. The insert with cells was placed in the lower chamber of a 24-chamber plate containing $600 \mu \mathrm{L}$ serum-free medium with added $40 \mathrm{ng} / \mathrm{mL}$ SDF-1. After $20 \mathrm{~h}$ of incubation at $37^{\circ} \mathrm{C}$, the lower-chamber medium was collected and the migrated cells in this medium were counted with a hemocytometer. All experiments were done in triplicates per sample. The data are presented as percentages of migrated cells to the total number of cells placed in the insert.

\section{Colony-forming unit assay}

The clonogenic potential of bone marrow stem progenitor cells were evaluated through 
a functional colony-forming unit (CFU) assay. The isolated BMMNCs were seeded (at $\left.1 \times 10^{5}\right)$ in six-well fibrinogen-coated plates. The plates were studied under a phase-contrast microscope, and the total CFU per well (one colony: $>50$ cells) was counted after 10 days of incubation at $37^{\circ} \mathrm{C}$ and $0.5 \%$ carbon dioxide. The CFUs were examined in duplicates per sample.

\section{Statistical analysis}

Statistical analysis was performed with SPSS software version 17.0 (SPSS Inc., Chicago, IL, USA). The data are presented as means \pm standard deviation. Two-way analysis of variance with correction for repeated measures was used for group comparison. Two-group comparisons were also undertaken by using Student $t$ - or $t^{\prime}$-test. Bivariate associations were analyzed by using Spearman correlation and linear regression. Statistical significance was assumed at a two-sided $P$ value of $<0.05$.

\section{RESULTS}

\section{Patient characteristics}

The baseline characteristics of the study population are shown in Table 1. The mean age of the population was 63.25 (SD 8.7) years. Most of the patients had triple-vessel disease (42, 93.2\%). The mean Euroscore was $3.89 \pm 3.0$.

\section{Table 1. Baseline characteristics of the patients.}

\begin{tabular}{|c|c|}
\hline Characteristics & \\
\hline Age (years) & $63.25 \pm 8.7$ \\
\hline Male, N (\%) & $34(65.9)$ \\
\hline Height (cm) & $166.5 \pm 7.1$ \\
\hline Weight (kg) & $70.1 \pm 9.1$ \\
\hline BMI & $25.6 \pm 2.8$ \\
\hline Hypertension, N (\%) & $32(72.7)$ \\
\hline Diabetes, $N(\%)$ & $20(45.5)$ \\
\hline Hyperlipidemia, N (\%) & $10(22.7)$ \\
\hline Smoking, N (\%) & $21(47.7)$ \\
\hline Current smoking, $\mathrm{N}(\%)$ & $12(27.3)$ \\
\hline Peripheral arterial disease, $\mathrm{N}(\%)$ & $13(29.5)$ \\
\hline Cerebrovascular disease, $\mathrm{N}(\%)$ & $4(9.1)$ \\
\hline $\operatorname{LVEF}(\%)$ & $61.6 \pm 11.0$ \\
\hline NYHA3-4, N (\%) & $9(20.5)$ \\
\hline Recent myocardial infarction, $\mathrm{N}(\%)$ & $7(15.9)$ \\
\hline Euroscore & $3.89 \pm 3.00$ \\
\hline Previous myocardial infarction, $\mathrm{N}(\%)$ & $13(29.5)$ \\
\hline Left main stem disease, $\mathrm{N}(\%)$ & $13(29.5)$ \\
\hline Triple-vessel disease, N (\%) & 42 (93.2) \\
\hline \multicolumn{2}{|l|}{ Routine laboratory examination } \\
\hline $\mathrm{Hb}(\mathrm{g} / \mathrm{L})$ & $135.1 \pm 14.9$ \\
\hline WBC $\left(\times 10^{9} / L\right)$ & $6.73 \pm 1.66$ \\
\hline Plt $\left(x 10^{12} / \mathrm{L}\right)$ & $214.2 \pm 44.4$ \\
\hline $\mathrm{HDL}(\mathrm{mM})$ & $1.08 \pm 0.21$ \\
\hline LDL (mM) & $2.53 \pm 0.81$ \\
\hline $\mathrm{TG}(\mathrm{mM})$ & $1.47 \pm 0.76$ \\
\hline Albumin (g/L) & $40.7 \pm 3.2$ \\
\hline \multicolumn{2}{|l|}{ Preoperative medication } \\
\hline Aspirin & $9.2 \pm 6.9$ \\
\hline Statins, N (\%) & $28(63.6)$ \\
\hline Beta blockers, $\mathrm{N}(\%)$ & $43(97.7)$ \\
\hline ACE inhibitors, $N(\%)$ & $17(86.4)$ \\
\hline ARB, N (\%) & $5(11.36)$ \\
\hline Calcium channel blockers, $\mathrm{N}(\%)$ & $20(52.3)$ \\
\hline
\end{tabular}




\section{Counts of BMMNCs}

We assessed whether the number of BMMNCs correlated with the perioperative risk factors. Age was the major risk factor that determines the number of BMMNCs isolated from a $20 \mathrm{~mL}$ bone marrow aspirate. As shown in Figure 1, we observed an inverse correlation between the subjects' age and level of BMMNCs $(r=-0.788, P<0.001)$. The numbers of BMMNCs were significantly reduced in patients with hyperlipidemia $(24.7 \pm 7.0$ [10] vs $33.7 \pm$ $19.1[34] \mathrm{P}=0.029)$.

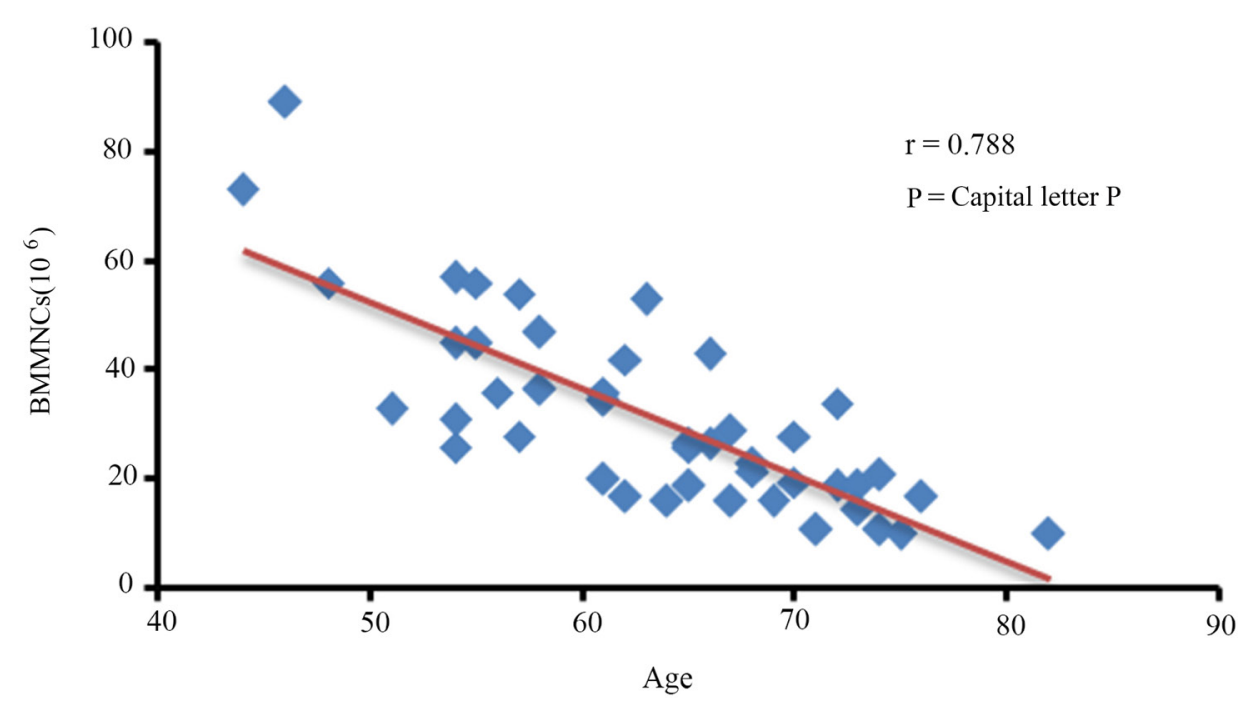

Figure 1. Association between bone marrow mononuclear cell (BMMNC) counts and age.

\section{Counts of bone marrow resident progenitor cells}

The level of CD34+ progenitor cells in BMMNCs was $0.94 \pm 0.39 \%$, CD133+ progenitor cells $0.46 \pm 0.28 \%$, and $\mathrm{CD} 34+\mathrm{CD} 133+$ progenitor cells $0.53 \pm 0.26 \%$. There were significantly lower levels of $C D 34+$ cells $(P=0.001)$ and $C D 133+$ cells $(P=0.001)$ in patients with diabetes. None of the cardiovascular risk factors influenced the level of CD34+CD133+ progenitor cells in the bone marrow.

\section{CFUs and cardiovascular risk factors}

We assessed whether the level of bone marrow progenitor cells correlated with the presence or absence of perioperative cardiovascular risk factors. The numbers of CFUs were significantly elevated in patients with a smoking history $(P=0.04)$, and reduced in patients with poor heart function $(P=0.019)$. As shown in Figure $2 A$, there was a negative correlation between age and CFUs $(N=44, r=-0.788, P<0.001)$. No other risk factor influenced the migration ability of BMMNCs, except for the level of CD34+ cells. There was a positive correlation between BMMNC migration and the level of CD34+ cells (Figure 2B). 
A

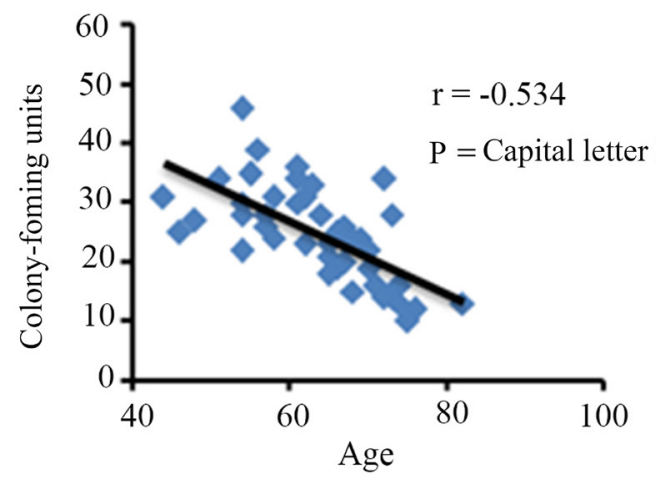

B

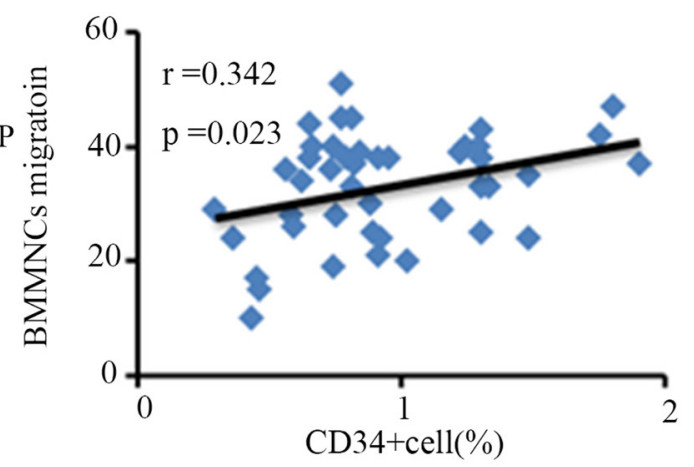

Figure 2. Factors influencing bone marrow resident progenitor cell function. A. Relation between colony-forming units of bone marrow progenitor cells and age. B. Bone marrow mononuclear cell (BMMNC) migration and level of CD34+ cells.

\section{DISCUSSION}

Bone marrow-derived stem cells are one of the most studied stem cell sources for stem cell therapy in ischemic heart disease. The clinical application of autologous bone marrow-derived cells has no ethical or immunologic problems. However, a previous study in animals demonstrated that many factors, such as aging and systemic diseases, contributed to the functional impairment of bone marrow cells (Lehrke et al., 2006; Li et al., 2006) Indeed, the outcome in some patients undergoing cell therapy for ischemic heart disease was poor (Wollert et al., 2004; Lunde et al., 2006; Schachinger et al., 2006). The risk factors that would probably influence bone marrow cells were not yet determined in detail in patients with coronary heart disease.

We assessed the numbers of BMMNCs in $20 \mathrm{~mL}$ bone marrow in duplicate samples from patients with coronary heart disease scheduled for CABG. We observed a decline in the numbers of BMMNCs with aging. However, the level of bone marrow resident progenitor cells was not correlated with aging, which was only lowered in patients with diabetes. The clonogenic function of bone marrow progenitor cells was elevated in patients with a smoking history, as opposed to being reduced in patients with poor heart function. No risk factors influenced the migration ability of bone marrow cells.

Most of the previous studies used BMMNCs as the cell source for stem cell therapy instead of isolated progenitor cells (Ang et al., 2008; Van Ramshorst et al., 2009), and in one of them, the bone marrow was obtained from the sternum (Zhao et al., 2008). If the sternum was used as the unique source of bone marrow, especially like in the previous study (Zhao et al., 2008), the number of BMMNCs is limited in elderly patients, according to our results. Meluzin et al. (2006) found an incremental improvement in left ventricular ejection fraction in a dose-dependent manner. However, Ellis et al. (2006) found no difference between low-dose and high-dose granulocyte colony-stimulating factor therapy groups. Further studies are needed to identify whether the abovementioned manner of obtaining BMMNCs would influence the outcome of clinical trials on cell therapy for ischemic heart disease.

In patients with coronary artery disease, aging is associated with a reduced number and function of circulating progenitor cells (Vasa et al., 2001; Werner et al., 2005). On the contrary, 
consistent with a previous study (Povsic et al., 2010), we did not find a correlation between aging and the level of bone marrow resident progenitor cells, and aging and function of bone marrow cells. These findings suggest that (i) aging does not result in depletion in the numbers of bone marrow resident progenitor cells, and (ii) the loss of circulating progenitors is not reflective of the underlying stores of bone marrow resident progenitor cells. The former observation has possible implications for the use of autologous sources of progenitor cells for cell therapy applications. However, Edelberg et al. (2002) demonstrated that young, but not old, bone marrow cells incorporated into the neovasculature and restored cardiac angiogenic functions. Interestingly, bone marrow cell therapy was more effective in aging patients with ischemic heart disease (Bai et al., 2010).

We observed a reduced level of progenitor cells in the bone marrow, but not of the progenitor cell function, in patients with diabetes. Diabetes is one of the key risk factors for coronary artery disease, and its prevalence has increased during the last few years. Analysis of cultured circulating endothelial progenitor cells (EPCs) and CD34+KDR+ cells, and their functions in clinical studies identified diabetes as a major determinant of impairment for circulating progenitor cells, which was in contrast to our result for bone marrow progenitor cells. Patients with type I and type II diabetes exhibit lower numbers of CD34+KDR+ EPCs or cultured EPCs (Loomans et al., 2004; Fadini et al., 2005; Thum et al., 2007), and the reduced number of CD34+KDR+ cells was associated with the severity of diabetic vasculopathy (Fadini et al., 2006). These results were consistent with animal experiments with obese diabetic mice, in which the function of progenitor and proangiogenic cells were impaired (Awad et al., 2005; li et al., 2006). Of note, diabetes was not only associated with the reduction of cell numbers but it also led to a profound impairment of cell functionality, such as reduced migration toward cytokines, reduced proliferation, and reduced ability of the cells to integrate into vascular networks in vitro (Tepper et al., 2002; Loomans et al., 2004). The impaired migratory response resembled the previously shown diminished response of diabetic monocytes to vascular endothelial growth factor Waltenberger $\mathrm{J}$ et al.,2000. Additionally, an increased sensitivity toward apoptosis or stress response of diabetic cells was described in some studies (Tepper et al., 2002; Awad et al., 2005), and high glucose concentrations induce senescence in cultured EPCs (Rosso et al., 2006). If cells isolated from patients with diabetes were used to therapeutically enhance blood flow recovery in ischemia models, transplanted cells were significantly less effective than healthy control-derived cells (Seeger et al., 2005; Walter et al., 2007). Likewise, the capacity of diabetic patient-derived cells to reendothelialize denuded arteries was impaired (Sorrentino et al., 2007). In skin wound assays, bone marrow-derived cells enriched for progenitor cells (lineage fraction) isolated from obese diabetic mice even decreased vascularization (Stepanovic et al., 2003). Such an inhibitory effect might be explained by the release of antiangiogenic factors (such as thrombospondin), which are increased in diabetic EPCs (li et al., 2006). In contrast, bone marrow cell therapy was more effective in diabetic patients (Bai et al., 2010), which demonstrated that bone marrow cell transplantation led to increased level and function of local progenitor cells that resulted in the improvement of cardiac function.

Similar to the impaired function of circulating or bone marrow-derived cells due to diabetes, other risk factors such as hypercholesterolemia (Vasa et al., 2001a) and hypertension (Vasa et al., 2001a; Pirro et al., 2007) were also associated with reduced and dysfunctional circulating EPCs. In addition, circulating progenitor cells were inversely correlated with smoking (Vasa et al., 2001; Kondo et al., 2004), and this reduction was reversed by smoking cessation (Kondo et al., 2004). Our results that the clonogenic function of bone marrow progenitor cells was elevated in patients with a smoking history demonstrated that smoking can decrease the migration ability of bone marrow cells. 
The ultimate goal of cardiac cell therapy is to treat patients with heart failure, which remains one of the major causes of mortality despite optimized pharmacological and interventional treatments. Several studies indicate that heart failure affects progenitor cell functions. A side-byside comparison of bone marrow-derived and circulating blood-derived cells in acute versus chronic heart failure showed a significantly diminished response of heart failure patients toward circulating progenitor cells (Assmus et al., 2006). Bone marrow cells isolated from bone marrow aspirates of patients with ischemic heart failure were less effective in improving the recovery of blood flow after hind-limb ischemia compared with healthy controls (Heeschen et al., 2004). Consistent with the previous study, our results showed that poor heart function was related with impaired function of bone marrow resident progenitor cells. This functional impairment of BMMNCs from patients with poor heart function may limit their therapeutic potential for clinical cell therapy.

\section{CONCLUSION}

Aging and diabetes were major risk factors that have an influence on the level and function of bone marrow resident progenitor cells in patients with coronary heart disease. Further study is needed to determine whether these two factors can influence the outcome of bone marrow cell therapy for ischemic heart disease.

\section{REFERENCES}

Ang KL, Chin D, Leyva F, Foley P, et al. (2008). Randomized, controlled trial of intramuscular or intracoronary injection of autologous bone marrow cells into scarred myocardium during CABG versus CABG alone. Nat. Clin. Pract. Cardiovasc. Med. 5: 663-670.

Assmus B, Honold J, Schachinger V, Britten MB, et al. (2006). Transcoronary transplantation of progenitor cells after myocardial infarction. N. Engl. J. Med. 355: 1222-1232.

Awad O, Jiao C, Ma N, Dunnwald M, et al. (2005). Obese diabetic mouse environment differentially affects primitive and monocytic endothelial cell progenitors. Stem Cells 23: 575-583.

Bai Y, Sun T and Ye P (2010). Age, gender and diabetic status are associated with effects of bone marrow cell therapy on recovery of left ventricular function after acute myocardial infarction: a systematic review and meta-analysis. Ageing Res. Rev. 9: 418-423.

Edelberg JM, Tang L, Hattori K, Lyden D, et al. (2002). Young adult bone marrow-derived endothelial precursor cells restore aging-impaired cardiac angiogenic function. Circ. Res. 90: E89-E93.

Ellis SG, Penn MS, Bolwell B, Garcia M, et al. (2006). Granulocyte colony stimulating factor in patients with large acute myocardial infarction: results of a pilot dose-escalation randomized trial. Am. Heart J. 152: 1051.e9-14.

Fadini GP, Miorin M, Facco M, Bonamico S, et al. (2005). Circulating endothelial progenitor cells are reduced in peripheral vascular complications of type 2 diabetes mellitus. J. Am. Coll. Cardiol. 45: 1449-1457.

Fadini GP, Sartore S, Albiero M, Baesso I, et al. (2006). Number and function of endothelial progenitor cells as a marker of severity for diabetic vasculopathy. Arterioscler. Thromb. Vasc. Biol. 26: 2140-2146.

Heeschen C, Lehmann R, Honold J, Assmus B, et al. (2004). Profoundly reduced neovascularization capacity of bone marrow mononuclear cells derived from patients with chronic ischemic heart disease. Circulation 109: 1615-1622.

li M, Takenaka H, Asai J, Ibusuki K, et al. (2006). Endothelial progenitor thrombospondin-1 mediates diabetes-induced delay in reendothelialization following arterial injury. Circ. Res. 98: 697-704.

Kondo T, Hayashi M, Takeshita K, Numaguchi Y, et al. (2004). Smoking cessation rapidly increases circulating progenitor cells in peripheral blood in chronic smokers. Arterioscler. Thromb. Vasc. Biol. 24: 1442-1447.

Lehrke S, Mazhari R, Durand DJ, Zheng M, et al. (2006). Aging impairs the beneficial effect of granulocyte colony-stimulating factor and stem cell factor on post-myocardial infarction remodeling. Circ. Res. 99: 553-560.

Li TS, Furutani A, Takahashi M, Ohshima M, et al. (2006). Impaired potency of bone marrow mononuclear cells for inducing therapeutic angiogenesis in obese diabetic rats. Am. J. Physiol. Heart Circ. Physiol. 290: H1362-H1369.

Loomans CJ, de Koning EJ, Staal FJ, Rookmaaker MB, et al. (2004). Endothelial progenitor cell dysfunction: a novel concept in the pathogenesis of vascular complications of type 1 diabetes. Diabetes 53: 195-199. 
Lunde K, Solheim S, Aakhus S, Arnesen H, et al. (2006). Intracoronary injection of mononuclear bone marrow cells in acute myocardial infarction. N. Engl. J. Med. 355: 1199-1209.

Meluzin J, Mayer J, Groch L, Janousek S, et al. (2006). Autologous transplantation of mononuclear bone marrow cells in patients with acute myocardial infarction: the effect of the dose of transplanted cells on myocardial function. Am. Heart J. 152: 975 e9-975e15.

Pirro M, Schillaci G, Menecali C, Bagaglia F, et al. (2007). Reduced number of circulating endothelial progenitors and HOXA9 expression in CD34+ cells of hypertensive patients. J. Hypertens. 25: 2093-2099.

Povsic TJ, Zhou J, Adams SD, Bolognesi MP, et al. (2010). Aging is not associated with bone marrow-resident progenitor cell depletion. J. Gerontol. A Biol. Sci. Med. Sci. 65: 1042-1050.

Rosso A, Balsamo A, Gambino R, Dentelli P, et al. (2006). p53 Mediates the accelerated onset of senescence of endothelial progenitor cells in diabetes. J. Biol. Chem. 281: 4339-4347.

Schachinger V, Erbs S, Elsasser A, Haberbosch W, et al. (2006). Intracoronary bone marrow-derived progenitor cells in acute myocardial infarction. N. Engl. J. Med. 355: 1210-1221.

Seeger FH, Haendeler J, Walter DH, Rochwalsky U, et al. (2005). p38 mitogen-activated protein kinase downregulates endothelial progenitor cells. Circulation 111: 1184-1191.

Sorrentino SA, Bahlmann FH, Besler C, Muller M, et al. (2007). Oxidant stress impairs in vivo reendothelialization capacity of endothelial progenitor cells from patients with type 2 diabetes mellitus: restoration by the peroxisome proliferatoractivated receptor-gamma agonist rosiglitazone. Circulation 116: 163-173.

Stepanovic V, Awad O, Jiao C, Dunnwald M, et al. (2003). Leprdb diabetic mouse bone marrow cells inhibit skin wound vascularization but promote wound healing. Circ. Res. 92: 1247-1253.

Tepper OM, Galiano RD, Capla JM, Kalka C, et al. (2002). Human endothelial progenitor cells from type II diabetics exhibit impaired proliferation, adhesion, and incorporation into vascular structures. Circulation 106: 2781-2786.

Thum T, Fraccarollo D, Schultheiss M, Froese S, et al. (2007). Endothelial nitric oxide synthase uncoupling impairs endothelial progenitor cell mobilization and function in diabetes. Diabetes 56: 666-674.

Van Ramshorst J, Bax JJ, Beeres SL, Dibbets-Schneider P, et al. (2009). Intramyocardial bone marrow cell injection for chronic myocardial ischemia: a randomized controlled trial. JAMA 301: 1997-2004.

Vasa M, Fichtlscherer S, Adler K, Aicher A, et al. (2001a). Increase in circulating endothelial progenitor cells by statin therapy in patients with stable coronary artery disease. Circulation 103: 2885-2890.

Vasa M, Fichtlscherer S, Aicher A, Adler K, et al. (2001b). Number and migratory activity of circulating endothelial progenitor cells inversely correlate with risk factors for coronary artery disease. Circ. Res. 89: E1-E7.

Walter DH, Rochwalsky U, Reinhold J, Seeger F, et al. (2007). Sphingosine-1-phosphate stimulates the functional capacity of progenitor cells by activation of the CXCR4-dependent signaling pathway via the S1P3 receptor. Arterioscler. Thromb. Vasc. Biol. 27: 275-282.

Waltenberger J, Lange J and Kranz A (2000). Vascular endothelial growth factor-A-induced chemotaxis of monocytes is attenuated in patients with diabetes mellitus: a potential predictor for the individual capacity to develop collaterals. Circulation 102: 185-190.

Werner N, Kosiol S, Schiegl T, Ahlers P, et al. (2005). Circulating endothelial progenitor cells and cardiovascular outcomes. N. Engl. J. Med. 353: 999-1007.

Wollert KC, Meyer GP, Lotz J, Ringes-Lichtenberg S, et al. (2004). Intracoronary autologous bone-marrow cell transfer after myocardial infarction: the BOOST randomised controlled clinical trial. Lancet 364: 141-148.

Zhao Q, Sun Y, Xia L, Chen A, et al. (2008). Randomized study of mononuclear bone marrow cell transplantation in patients with coronary surgery. Ann. Thorac. Surg. 86: 1833-1840 